\title{
Supply and Demand Analysis of High-End Talents in Liaoning Province
}

\begin{abstract}
Bao Wen Li
School of management, Liaoning Institute of Science and Technology, Benxi, Liaoning, China 747767478@qq.com

ABSTRACT

The researcher first analyzes the supply situation of talents with master's degree or above in Liaoning Province from two aspects of total amount and distribution, then analyzes the development trend of industrial structure, the development status of high-tech industry, the demand trend of high-end talents in the industry, and the demand situation of high-end talents in enterprises. The results show that salary is the condition to attract talents, while environment and career development are the secret to retain talents. This paper summarizes the problems in talent supply: the lack of quality inspection and professional early warning mechanism. Finally, suggestions are given from four aspects: establishing a feedback database system of employers, strengthening professional adjustment and optimizing macro guidance; establishing a feedback data system of graduates, regularly forming a report system of employment quality, publicly releasing reports, which can be widely used by all sectors of the society; taking industrial structure adjustment as the goal, University majors need to be optimized, adjusted, upgraded, replaced and newly built; construction of organizational human environment.
\end{abstract}

Keywords: High level talents, supply, demand

\section{辽宁省高端人才供给和需求分析}

\author{
包文莉
}

辽宁科技学院管理学院, 本溪, 辽宁, 中国

747767478@qq.com

\section{摘要}

研究者首先从总量和布点两方面分析了辽宁省硕士及以上学历人才的供给状况, 然后分析了辽宁省产 业结构发展趋势, 高技术产业的发展现状, 产业高端人才需求的趋势, 企业高端人才的需求状况。分 析了工作所需能力和人才跳槽的原因, 结果表明, 工资是吸引人才的条件, 而环境和职业生涯发展是 留住人才的秘籍。总结了人才供给方面存在的问题：质量检测和专业预警机制缺乏。最后从建立用人 单位反馈数据库系统, 加强专业调整和优化宏观指导; 建立毕业生反馈数据系统, 定期形成就业质量 报告制度, 公开发布报告, 社会各界可以广泛应用报告; 以产业结构调整为目标, 大学专业需要优化、 调整、升级、换代和新建; 组织人文环境建设四个方面给出建议。

关键词: 高端人才, 供给, 需求

\section{1. 引言}

2020 年 1 月 6 日, 辽宁省人力资源与社会保障厅下 发了《关于开展有关补贴、资助和奖励申报工作的通 知》，切实做好《辽宁省人才服务全面振兴三年行动计
划（2018-2020 年）》（辽委办发（2018） 25 号）、 《关于推进人才集聚的若干政策》（辽委办发 (2018) 76 号) 等人才政策的落实工作, 确保人才政策真正落地 见效. 积极兄现人才政策, 让人才享受到政策红利, 发 挥人才政策效用。在现代企业和经济发展中，人才是一 种无法估量的资本，把人的智慧能力作为一种巨大的资 源进行挖掘和利用, 才能达到科技进步和经济腾飞。人 
社厅的这一通知, 体现了辽宁省对人才的重视和留在人 才的决心。

本研究立足于辽宁实际, 着眼于解决以下问题: 辽 宁省的人才供给现状如何？人才跳槽的原因是什么? 什么样的人才算是人才? 辽宁省缺什么样的人才? 企 业如何才能吸引和留住人才? 本研究为辽宁企业更好 地留才提供切实可行的建议, 对于增强辽宁企业的竞争 能力, 提升高校人才培养的质量和水平具有重要的意 义。

\section{2. 辽宁省高端人才的供给状况}

2015 年-2018 年辽宁普通高校博士招生计划人数稳 定, 每年都在 0.3 万人左右, 硕士生逐年扩招。硕士毕 业生近 5 年相应呈上升趋势。

辽宁省高校每年毕业和招生的人数最多的研究生 专业是工学, 其次是医学、管理学、理学、法学、经济 学、教育学、文学、艺术学、农学、哲学、历史学。这 与全国研究生各学科学生数量情况差异不大。

工学专业研究生布点在辽宁超过 10 个的专业分别 是: 计算机应用技术、应用化学、机械设计及理论、控 制理论与控制工程、机械工程、材料加工工程、材料学、 机械制造及其自动化、计算机软件与理论、控制科学与 工程。根据全国布点的情况, 辽宁工学专业占比较小的 专业分别是: 电磁场与微波技术、物理电子学、微电子 学与固体电子学、电路与系统、地球探测与信息技术、 精密仪器及机械、食品科学、粮食、发酵工程、油脂及 植物蛋白工程、水力学及河流动力学、电子科学与技术、 仪器科学与技术、农产品加工及败藏工程、测试计量技 术及仪器、航空宇航科学与技术。

辽宁省管理学专业研究生布点最多的是企业管理、 管理科学与工程、会计学、技术经济及管理、旅游管理、 行政管理、工程管理等。根据全国布点的情况, 辽宁管 理学专业占比较小的专业分别是: 图书情报、图书情报 与档案管理、农业经济管理、情报学、公共管理、图书 馆学、林业经济管理、社会医学与卫生事业管理、土地 资源管理、档案学、公共管理。

辽宁省经济学专业研究生布点最多的是: 西方经济 学、经济思想史、经济史、产业经济学、政治经济学、 理论经济学、世界经济、国际贸易学、金融学、财政学。 根据全国布点的情况, 辽宁管理学专业占比较小的专业 分别是: 数量经济学、劳动经济学、国际商务、人口、 资源与环境经济学、国防经济、资产评估、审计、税务、 保险。

辽宁省哲学专业研究生布点最多的是伦理学、马克 思主义哲学、科学技术哲学、中国哲学、外国哲学。缺 乏布点的哲学专业是美学、宗教学。

\section{3. 辽宁省高端人才的需求状况}

高等教育所培育的人才, 一方面在总量上要与社会
经济发展总量相适应, 另一方面要求高等教育的人才输 出结构能够满足国民经济产业结构的需求。高等教育结 构对产业结构有反作用。这种反作用体现在高等教育发 展要立足于世界各国产业结构的升级规模之上, 适度先 行于本国产业结构。

\section{1. 辽宁省产业结构发展趋势}

3. 1. 1. 辽宁省三次产业对经济增长的贡献率越来越大。 从三次产业对经济增长的贡献率来看, 第三产业逐渐成 为主导。第一产业就业人员比例与其对经济发展贡献率 不匹配。通过分析三次产业结构偏离度也可以发现, 辽 宁第一产业的劳动生产率很低, 存在转出的可能性。

3. 1.2. 辽宁省第三产业就业人员数量逐年稳步增长。第 三产业逐渐成为就业主体。从全国范围来看, 辽宁省 GDP 增量和三次产业结构水平处于中间水平。2018 年辽宁省 第三产业增量水平在全国排名第九。与全国对比来看, 我省还是农业大省, 农业就业人员比重高于工业就业人 员。按照世界经济发展规律, 三次产业对经济发展贡献 率和从业人员数量还将逐年上升。

3.1.3. 发展态势预测, 我省第三产业在未来 10 年将呈 现增长趋势, 第一、第二产业在未来 10 年将出现下降 趋势。采取专家建模器方法, 利用产业分行业增加值对 三次产业分行业发展状况进行原值静态预测, 我省第一 产业在未来 10 年将呈现下降趋势。第二产业工业在未 来 10 年将出现下降趋势, 建筑业在未来 10 年将呈现上 升趋势。第三产业中的交通运输、住宿业未来 10 年将 保持平稳态势; 金融业、服务业将出现大幅度上升态势; 房地产、批发零售业将出现小幅上升趋势。采取专家建 模器方法, 对发展速度进行动态预测, 第三产业发展速 度将保持平稳，其中交通、批发、住宿、金融和其它服 务业的动态发展速度将保持平稳, 农业、工业、建筑业 的发展速度呈现下降趋势。

整体来说, 辽宁省三次产业结构存在的现状是: 按 照对经济的贡献水平看, 第一产业劳动力过多; 第二产 业对经济贡献率降低, 劳动力吸纳数量下降; 第三产业 对经济贡献越来越大, 吸纳能力有待提升。未来发展可 能如下: 随着收入水平的提高, 人们对农产品需求的增 加小于工业和服务业产品所需求的増加; 农业投资报酬 低, 收入水平低; 农业部门的劳动生产率随着技术进步 水平的提升也逐步提高, 农业部门本身对劳动力产生排 挤效应, 大量劳动力从农业中走出, 需要技能的提升, 农业对于研究型劳动力的需求将上升, 职业教育对于这 些劳动力尤显重要。第二产业劳动力比重下降, 占国民 经济比重下降, 未来发展工业部门术进步导致资本有机 构成的提高, 会抑制劳动力的需求, 规模扩大与有机构 成提高, 工业部门劳动力比重下; 第三产业中的金融业、 
其它社会服务业劳动力比重将进一步上升。

\section{2. 辽宁看高技术产业的发展情况}

高技术产业是国家产业发展的趋势，对于改变和优 化产业结构, 促进经济发展具有重要的意义。根据我国 高技术产业统计年鉴，辽宁省航空、航天器及设备制造 业经营状况在全国居于前茅, 医疗仪器设备及仪器仪表 制造业经营状况在全国处于中等偏上位置, 医药制造 业、电子及通信设备制造业、计算机及办公设备制造业、 信息化学品制造业经营状况在全国处于下游。

\section{3. 产业高端人才需求的趋势}

从发展趋势看, 各行业大学劳动力比重呈现上升趋 势, 除了公共管理、水利、住宿行业有下降趋势外。从 整体来看, 专科整体呈现下降趋势, 本科整体呈现上升 趋势, 这与整个社会大学劳动力供给有关。硕士及以上 高学历人才集中在科学研究、教育、信息传输、卫生社 会工作、金融业、文化体育行业。这与整个社会高学历 人才供给状况出现相关性。也体现了罗斯托发展模式。

\section{4. 辽宁省企事业单位高端人才的需求状况}

研究团队在 2020 年 1-3 月, 通过辽宁省人事网收 集辽宁企事业单位高端人才需求信息, 共收集到 2019 年全年需求信息 5898 条, 利用大数据分析软件 NLPIR, 对收集到的招聘信息进行文本分析, 一是 2019 年辽宁 高端人才需求前六名专业: 医学大类、思想政治教育类、 经济管理类、电子信息计算机类、理学类、农学类。二 是理学中的微生物、物理、医学中的放射、影像、药理, 法学中的民商法, 农学中的作物, 艺术学中的俄语语言 文学、工学中的飞行器设计、测量、材料, 管理学中会 计、物流管理。是出现频次最高的专业关键词。三是工 程、科学技术、医学、化学、经济学、电子、计算机、 机械成为出现次数最多的名词。这受到国家的方针政策 的影响和经济发展水平的影响。四是计算机科学与技 术、机械设计制造及其自动化、信息管理与信息系统、 工商管理、环境工程、法学、通信工程、土木工程、测 控技术与仪器、自动化、日语、电子信息工程这几个专 业硕士及以上的招聘岗位数比本科招聘岗位数多, 这些 专业对于本科生来说可能读研究生就业机会更多。

\section{5. 工作所需能力}

文科和理工科毕业生同时认为重要的能力包括学 习能力、专业知识和技能, 文科生认为, 沟通和表达是 职业生涯各阶段都需要的重要能力。随着职业生涯的发 展, 理工科毕业生认为创新能力越来越重要, 文科毕业 生认为专业技能越来越重要。

\section{6. 人才跳槽的原因}

通过访谈 340 名硕士及以上学历员工, 工资低是人 才跳槽的首要原因。工资是吸引人才的条件, 而环境和 职业生涯发展是留住人才的秘籍。根据词频分析, 尝试 分析工作变化次数、性别、毕业时间、收入的相关关系, 结果表明工作变化次数与毕业时间、收入情况显著正相 关。结合相关分析和换工作词频分析, 工资低是换工作 的主要原因。随着工作时间的推移, 个人由于自己家庭、 需求层次的提升、对环境的追求等各种原因, 出现跳槽 现象。

\section{7. 组织文化环境的建设}

家庭、需求层次的提升这些主观原因不可控性强, 我们不多做分析。环境组织可以营造。那么员工究竟需 要什么样的环境呢? 我们就此问题, 开展了组织人文环 境与员工组织认同度的深度调研。此次共调查了 46 家 企业 492 名大学本科及以上学历的员工。通过多元因果 关系分析, 得出以下结论。

1. 整个组织很讲究权威等级, 那么最好招聘价值观 认同领导权威、等级的人员到组织工作。

2. 集体主义精神越强的人越容易形成对组织的认 同，而集体主义分值很低时，即缺乏个体服从集体的精 神时, 对组织认同度不易形成。

3. 讲究关系、和谐对雇员组织认同组织影响不大。

4. 在组织中要确保对雇员的物质需求保证。物质激 励很高却不一定导致高的组织认同。

5. 在组织日常管理文化建设中, 要善于运用工作授 权、规划员工职业生涯、人尽其才物尽其用，人岗匹配、 并对员工的工作成绩给予及时及时恰当的认可。

\section{4. 存在的问题}

\section{1. 就业质量监测问题}

1. 缺乏地区性的质量报告。现在人才培养质量报告 主要是各大高校自己负责, 没有第三方权威部门公平、 公正、公开评估各专业就业质量, 供高校、政府、家长 选择做参考。如果以各高校的毕业生质量调查为准, 会 存在以下问题: 王婆卖瓜自卖自夸现象; 各高校公布的 质量报告五花八门, 内容体系较为混乱。

2. 各单位机构、高校的就业状况监测指标体系不 同，全国缺乏统一的、健全的数据信息网络系统。

3. 政府与高校的就业数据信息不能及时共享，查阅 信息很困难。

4. 社会对于高端人才就业状况统计及监测的关注 度、参与度较低, 主要还是政府和高校两方在进行相关 研究与建设。

5. 在相关的法律、法规制定方面比较欠缺, 在动态 
跟踪数据的建设上比较薄弱, 各高校和地方政府对于就 业统计的重视度高于监测。

6. 监测指标设定在各高校和学者的研究中有分歧。

\section{2. 专业预警机制缺乏}

目前辽宁省各专业是否招生, 招生多少的预警机制 采取就业率、政府机构统计结果、论文质量抽查等方法, 存在的问题是如果以就业率为基础, 会存在指标单一, 信息准确性很难检测, 不能准确反映出高端人才培养质 量的真实水平。而毕业论文质量抽查是静态的方法, 主 观性较强, 对于毕业生的职业生涯跟踪和反馈改进教学 这块是缺乏的。

\section{5. 对策建议}

\section{1. 建立用人单位反馈数据库系统, 加强专 业调整和优化宏观指导}

专业的建设, 关系经济发展和未来, 毕业生的就业 状况影响重大。建议各地区政府部门、高校广泛布局各 区域、行业、不同性质的用人单位毕业生定点就业观测 点, 形成综合数据采集网络, 进行专业需求预测, 结合 供给情况, 探索形成专业发展预警, 并不断完善, 加强 专业调整和优化的宏观指导, 社会可查询可参与, 并形 成长效机制。

5. 2. 建立毕业生反馈数据系统, 定期形成就业质量报告 制度，公开发布报告，社会各界可以广泛应用报告

1. 政府需要总体把握高校毕业生就业形势。政府负 责就业状况统计及监测工作报告的主要部门, 形成统 一、高效毕业生就业质量年度报告标准化体系。

2. 政府指导高校建立毕业生数据采集系统。高校同 毕业生保持密切联系, 强化毕业生跟踪服务制度, 有法 律制度保障和激励措施保证毕业生全面参与, 确保数据 全面真实。形成全过程长周期数据采集制度, 如毕业半 年、毕业 3 年、 5 年、 10 年、 20 年为时间节点, 通过毕 业生的反馈改进课程设置, 推动学校教育教学改革, 为 专业优化设置提供参考, 促进高校和政府有效加强就业 指导的针对性。

3. 政府部门需要加强就业状况统计监测的领导工 作, 提供法规保证, 健全统计工作组织队伍, 完善信息 化系统，积极培育第三方公益组织机构。

4. 用人单位、高校、社会组织的数据互通互联, 避 免形成信息和数据孤岛。

5. 结果应用方面, 家长、学生可以方便查询高校之 外组织提供的高校就业质量信息，为选择做参考。

\section{2. 以产业结构调整为目标, 大学专业需要 优化、调整、开级、换代和新建}

以第一产业为例, 辽宁省工学专业本科占比全国专 业布点较小的专业分别是农业机械化及其自动化。辽宁 省工学专业占比较小的专业分别是：食品科学、粮食、 油脂及植物蛋白工程、农产品加工及陉藏工程。农业研 究生招生人数只比哲学和历史高点, 高端研究型人才供 给相对缺乏。辽宁省是农业大省, 农业吸纳的劳动力仅 次于第三产业, 而产出占比却很低, 第一产业劳动生产 率相对来说不高, 而第一产业大学劳动力占比相对低。

以第二产业为例, 我省优势高新技术产业航空航天 及设备制造业、电子通信设备制造业，辽宁省高端装备 制造、石化、电子信息、原材料深加工等支柱面临产业 转型升级, 大数据、人工智能、机器人、生命、能源、 材料、海洋等战略性新兴产业亟待发展壮大, 但是这些 专业专科层次人才供给相对较多, 研究生、博士层次的 供给相对较少。如, 辽宁省工学专业占比较小的专业分 别是: 电磁场与微波技术、物理电子学、微电子学与固 体电子学、电路与系统、地球探测与信息技术、精密仪 器及机械、水力学及河流动力学、电子科学与技术、仪 器科学与技术、测试计量技术及仪器、航空宇航科学与 技术。这些专业高端人才对于辽宁省高技术产业发展具 有重要作用。

\section{3. 组织从以下几个方面建设人文环境，以 留住人才}

1. 降低权利距离。权利距离越高的组织越讲究等 级、领导权威、下属的服从。高权利距离使员工不能知 无不言、言无不尽, 高层很难听到基层的内心真实想法, 了解到真实情况, 并且使能干又受欢迎的聪明员工变成 精明员工: 回报高于承担的工作。组织官僚主义滋生, 缺乏活力。对权利追求的心理易造成对下属不授权, 形 成下属无权之害, 降低员工的努力程度。

2. 引入职业经理人制度, 减少关本位现象。在阴柔 气质的文化中更讲究良好和谐、相互依赖的关系。实证 表明这种阴柔文化对员工组织认同并没有产生显著的 影响。追求裙带、亲缘关系形成权利寻租, 影响决策; 过于紧密的关系容易形成排外刚性, 使组织固步自封, 不能接纳新加入者, 使新加入者组织认同度降低, 更不 利于组织的创新效率。应该在组织内部尽力避免这种 “官” 本位现象。引入职业经理人制度, 而非亲缘关系 提升, 这样更有利于组织的发展。

3. 提高招聘过程的科学性。因人设岗, 或内部靠关 系提升, 这样会对组织造成灾难性的影响。其次招聘中 吸纳集体主义和家庭观念强的人。在集体主义文化影响 下，好的环境、学有所用、能够从工作中提升自己。当 个体具备这些价值观时更易形成对组织认同相对于不 具备这些价值观念的个体, 决策时更容易从集体的角度 思考问题。但这些因素程度越高却不足以增强对组织认 同感。在集体主义文化的影响下，个体家庭观念越强的 
人组织认同度越高, 这在组织招聘中值得参考。

4. 做好物质和非物质激励。组织提供给个体的可用 满足个人需求、影响个人动机的诱因必须等于或大于个 人对组织的贡献, 组织才能实现内部平衡, 获取成员较 高程度的努力和组织效率。非经济诱因超过物质诱因确 保个人协作努力。非物质激励因素中, 工作授权、满足 发展需求、对工作的喜爱、工作得到认可对员工组织认 同有积极的影响。在组织管理实践中从高层要保证对授 权、满足员工发展、及时恰当的工作认可这些增强组织 认同因素的推崇, 形成各级管理者的管理惯例。这样优 秀的员工才能留下。

\section{项目基金}

本文是辽宁省社科联课题“辽宁省高校毕 业生 供 给 需求大数 据分析 （20201s1ktyb-057）”的阶段研究成果之一。

\section{REFERENCES}

[1] Shen, C. W. (2019) Research on statistics and monitoring of employment status of college graduates. Beijing University of Aeronautics and Astronautics Press. Beijing.

[2] China HowNet. (2018) Liaoning statistical year. https://www.cnki.net/.

[3] China HowNet. (2017) China high tech statistics year. https: //www.cnki.net/. 